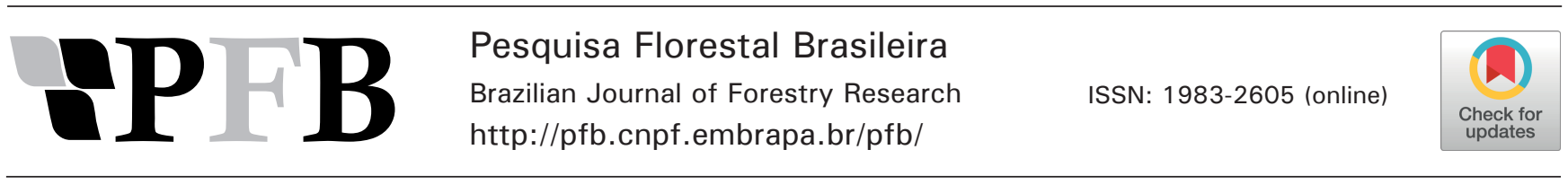

\title{
Respostas ecofisiológicas de Aniba parviflora ao sombreamento artificial
}

Cristina Aledi Felsemburgh ${ }^{1 *}$, Keilla Jeanne Silva dos Santos ${ }^{1}$, Plínio Barbosa de Camargo ${ }^{2}$, Janaina Braga do Carmo ${ }^{3}$, Edgard Siza Tribuzy ${ }^{1}$

${ }_{1}^{1}$ Universidade Federal do Oeste do Pará, Av. Vera Paz, s/n, CEP 68035-110, Santarém, PA, Brasil

2Universidade de São Paulo, Centro de Energia Nuclear na Agricultura, Av. Centenário, 303, CEP 13416-903, Piracicaba, SP, Brasil

${ }^{3}$ Universidade Federal de São Carlos, Rodovia João Leme dos Santos, (SP-264), Km 110, s/n, CEP 18052-780, Sorocaba, SP, Brasil

"Autor correspondente:

crisalefel@gmail.com

Termos para indexação:

Crescimento

Clorofila

Macacaporanga

Index terms:

Growth

Chlorophyll

Macacaporanga

\section{Histórico do artigo:}

Recebido em 29/06/2015

Aprovado em 12/08/2016

Publicado em 30/09/2016

doi: 10.4336/2016.pfb.36.87.964

\begin{abstract}
Resumo - Com o objetivo de avaliar as respostas ecofisiológicas de mudas de macacaporanga (Aniba parviflora) em diferentes níveis de sombreamento, foi conduzido um experimento em viveiro de mudas em condições de clima tropical chuvoso durante um ano. Os níveis de sombreamento foram 30\%, 50\% e 70\% e a pleno sol. Avaliouse altura, diâmetro, número de folhas, área foliar, área foliar específica, massa seca das raízes, caule, folhas e total, taxa assimilatória líquida, condutância estomática, transpiração, eficiência do uso da água e teores de clorofila. Os maiores valores para altura, área foliar, área foliar específica, taxa assimilatória líquida, condutância estomática, transpiração, eficiência do uso da água, clorofilas $a, b$ e total foram obtidos sob $70 \%$ de sombreamento. No entanto, para diâmetro, número de folhas, massa seca das raízes, caule, folhas e total os maiores valores foram sob $50 \%$ de sombreamento. Os resultados mostram que, em condições naturais, a espécie apresentaria melhores chances de regeneração sob cobertura da mata, tolerando inclusive intensidades luminosas bastante reduzidas, em decorrência de um dossel fechado, característica de planta secundária tardia.
\end{abstract}

\section{Ecophysiological responses of Aniba parviflora under artificial shading}

\section{Introdução}

Luz, disponibilidade de água, temperatura e condições edáficas são alguns dos elementos do ambiente que influenciam o desenvolvimento da vegetação. $\mathrm{O}$ suprimento inadequado de um desses fatores pode reduzir o vigor da planta e limitar seu desenvolvimento (Lima Junior et al., 2006; Lima et al., 2010; Santos et al., 2014). A luz é um fator ecológico de fundamental importância, capaz de interferir sobre todos os estádios de desenvolvimento das plantas e em seus numerosos processos fisiológicos (Lima et al., 2010). Desempenha 
um papel relevante na regulação da produção primária, contribuindo de forma efetiva para o crescimento das plantas. Geralmente, as características inerentes ao crescimento são utilizadas para inferir o grau de adaptabilidade à baixa disponibilidade de luz. O sucesso na adaptação de uma espécie em diferentes condições de irradiância está relacionado com a eficácia e rapidez com que os padrões de alocação de biomassa e comportamento fisiológico são ajustados (Campos \& Uchida, 2002; Lima et al., 2008).

Florestas tropicais possuem um mosaico de diferentes ambientes, variando de sub-bosques sombreados a clareiras de vários tamanhos, causadas por queda de árvores, levando a uma grande heterogeneidade de adaptações a esses diferentes gradientes de luz (Valladares et al., 2000). A elevada riqueza de espécies das florestas tropicais proporciona espécies congêneres que podem especializar-se ao longo deste gradiente de luz.

A heterogeneidade dos gradientes de luz no ambiente pode causar modificações na troca gasosa e desenvolvimento do vegetal, afetando a produtividade das plantas (Terashima \& Hikosaka, 1995). Espécies típicas de clareiras geralmente exibem altas taxas de crescimento e rápida renovação das folhas, enquanto espécies típicas de sub-bosques sombreados exibem baixas taxas de crescimento e lenta renovação foliar (Kitajima, 1994; Strauss-Debenedetti \& Bazzaz, 1996).

A plasticidade fenotípica é a capacidade de um genótipo de manifestar fenótipos distintos em resposta a um estímulo do ambiente (Briggs \& Walters, 1997). A luminosidade do habitat pode promover alterações fenotípicas tanto na morfologia quanto na fisiologia dos indivíduos (Lüttge, 1997). Alguns estudos mostram uma maior plasticidade fotossintética em espécies dependentes de clareiras quando comparadas às espécies tolerantes a sombra (Bazzaz \& Carlson 1982, StraussDebenedetti \& Bazzaz, 1996). A plasticidade fenotípica pode ser essencial para a sobrevivência em ambientes heterogêneos e variáveis (Bradshaw, 1965; Pintado et al., 1997).

A maior ou menor plasticidade adaptativa das espécies às diferentes condições de radiação solar depende do ajuste de seu aparelho fotossintético, de modo a garantir maior eficiência na conversão da energia radiante em carboidratos e, consequentemente, maior crescimento (Campos \& Uchida, 2002). Estudos relacionando à disponibilidade da radiação luminosa e à produção de mudas de espécies arbóreas de boa qualidade são importantes para o desenvolvimento das atividades florestais (Lima et al., 2010), sendo a prática de sombreamento artificial realizada por meio do uso de telas de sombreamento, método que tem sido amplamente utilizado para o conhecimento das necessidades luminosas (Dutra et al., 2012) e da ecofisiologia das espécies (Aguilera et al., 2004; Aguiar et al., 2011).

De acordo com Kubitzki \& Renner (1982), o centro de diversidade do gênero Aniba parece ser na região dos escudos das Guianas Sul-Americanas, Amazônia Central e, em segundo plano, nas áreas próximas ao Rio Ucayalí e o médio Rio Madeira, com ampla distribuição, podendo ser encontrado no Suriname, Guiana Francesa, Peru, Colômbia, Equador, Venezuela e na Amazônia Brasileira (O Extrativismo..., 1972). No Brasil, seu habitat ótimo é o alto e médio Amazonas e ocorre mais abundantemente no Amapá e na fronteira com a Guiana Francesa (Costa et al., 1995). Ocorre com maior frequência em ambientes de terras firmes e altas, principalmente em matas pluviais não inundáveis, ao longo das margens dos rios (Santana, 2000).

Aniba parviflora (Meisn.) Mez., também conhecida como macacaporanga, é uma espécie nativa da Amazônia pertencente à família Lauraceae. A macacaporanga é uma espécie aromática, destacando-se pela produção de óleo essencial cujo componente principal é o linalol, produto químico que pode ser transformado em um número de derivados de valor agregado para a indústria de fragrâncias (Rodrigues, 1989; Maia \& Andrade, 2009). Por apresentar estas características, tem sido vista como uma espécie com o mesmo potencial de utilização que o pau-rosa (Aniba rosaeodora Ducke) que, devido a sua intensa exploração para uso como madeira serrada e produção de óleo essencial, está classificada na categoria "em perigo" de extinção, de acordo com a Portaria $n^{\circ}$ 443, de 17 de dezembro de 2014, do Ministério do Meio Ambiente (Brasil, 2014). Apesar de sua importância, ainda são carentes os estudos sobre o crescimento da espécie na fase jovem.

Este trabalho teve como objetivo avaliar o efeito de diferentes níveis de sombreamento no crescimento inicial e nos parâmetros morfofisiológicos de mudas de Aniba parviflora em viveiro, para entender as estratégias de regeneração e a que grupo ecológico a espécie pertence. 


\section{Material e métodos}

O trabalho foi realizado no viveiro de mudas da Universidade Federal do Oeste do Pará, em Santarém, PA. Situado a uma latitude de $02^{\circ} 25^{\prime} 04 \mathrm{~S}$, longitude 544ㄴ'W de GRT e altitude de $51 \mathrm{~m}$ acima do nível do mar; o tipo climático é o Ami da classificação de Köppen (clima tropical chuvoso). A região apresenta uma estação seca, com precipitação média em torno de $54,8 \mathrm{~mm} \mathrm{mês}^{-1}$ de agosto a novembro e uma estação chuvosa caracterizada com média mensal em torno de $211,3 \mathrm{~mm}$. A temperatura média anual é de $25^{\circ} \mathrm{C}$ e a umidade relativa média do ar é de $85 \%$ (Instituto Nacional de Meteorologia, 2013). Durante o período de estudo, a temperatura média no viveiro foi de $27{ }^{\circ} \mathrm{C}$, com máxima de $31,2{ }^{\circ} \mathrm{C}$ e mínima de $22,3{ }^{\circ} \mathrm{C}$. A precipitação média foi de $171,6 \mathrm{~mm}$ e a umidade relativa média foi de $88 \%$. A radiação fotossinteticamente ativa (RFA) média foi de $26,7 \mathrm{~mol} \mathrm{~m}^{-2} \mathrm{dia}^{-1}, 18,1 \mathrm{~mol} \mathrm{~m}^{-2} \mathrm{dia}^{-1}$, $14,2 \mathrm{~mol} \mathrm{~m}^{-2} \mathrm{dia}^{-1}$ e $7,3 \mathrm{~mol} \mathrm{~m}^{-2}$ dia $^{-1}$ nos tratamentos com $0 \%, 30 \%, 50 \%$ e $70 \%$ de sombreamento, respectivamente, no horário entre 9 e $16 \mathrm{~h}$. O trabalho foi conduzido no período de dezembro de 2012 a dezembro de 2013.

Os frutos foram coletados de uma matriz na Fazenda Experimental Curauá, pertencente à empresa Pematec (Peças e Materiais Tecnológicos para Indústria Automobilística) localizada no Km 26 da Rodovia Curuá-Una, Santarém, PA. As sementes foram tratadas e germinadas em caixas plásticas, contendo duas folhas de papel de filtro no fundo, embebidas em água destilada. As caixas com as sementes foram mantidas em câmara de germinação à temperatura de $25^{\circ} \mathrm{C}$, sob fotoperíodo de 12 h. Para manter a homogeneidade, após a germinação, as plântulas de tamanho semelhante foram selecionadas e transferidas para vasos plásticos, com capacidade de 5,0 L, contendo como substrato $40 \%$ de solo inerte e $60 \%$ de composto orgânico, aos quais se adicionou $25 \mathrm{~g}$ de NPK (4-14-8) em cada vaso.

As mudas passaram por um período de 60 dias para estabelecimento nos vasos e após este período foram submetidas aos tratamentos de sombreamento. No tratamento controle, as mudas foram expostas à radiação solar direta, sem sombreamento artificial, e nos outros três tratamentos as plantas foram sombreadas com telas sombrite de cor preta com malhas causando 30\%, 50\% e $70 \%$ de sombreamento, sendo medida a irradiância em cada tratamento.
Após a indução dos tratamentos foram, realizadas as medições de altura das plantas $(\mathrm{H})$, com trena, e diâmetro do colo (D), com paquímetro digital. Essas medições foram repetidas a cada 60 dias, durante um período de 300 dias. Ao final do experimento, avaliouse, também, o número de folhas (NF) e área foliar (AF), com sistema de análise de imagens WinDIAS (modelo W-C110-PC, Delta-T Devices Ltd, Cambridge, UK). As trocas gasosas foliares foram determinadas com o analisador de gás por infravermelho LI-COR 6400 (LICOR, Inc,Lincon, NE, USA), avaliando-se a taxa assimilatória líquida $(A)$, condutância estomática $\left(g_{s}\right)$ e transpiração $(E)$, com a intensidade luminosa mantida em $1000 \mu \mathrm{mol} \mathrm{m} \mathrm{m}^{-1}$ (saturação de luz), $\left[\mathrm{CO}_{2}\right] \mathrm{em}$ $370 \mu \mathrm{mol} \mathrm{mol}^{-1}$ e temperatura em $29 \pm 1{ }^{\circ} \mathrm{C}$. A eficiência do uso da água (EUA) foi calculada pela razão $A / E$. As medidas foram realizadas entre $7 \mathrm{e} 12 \mathrm{~h}$. Os teores de clorofila $a, b$, total $(a+b)$ e razão $\mathrm{Cl} a / \mathrm{Cl} b$ foram determinados pelo método de Lichtenthaler (1987).

Para a quantificação da massa seca, as partes das mudas foram separadas, colocadas em sacos de papel e secas em estufa a $60^{\circ} \mathrm{C}$, durante $72 \mathrm{~h}$. Após esse período, foi determinada a massa seca das raízes (MSR), do caule (MSC), das folhas (MSF) e total (MST), verificados com auxílio de balança analítica (modelo AUW220D, Shimadzu Corp., Kioto, Japan). Calculou-se a razão raiz/ parte aérea (R/PA) e a área foliar específica (AFE) foi obtida pela razão $\mathrm{AF} / \mathrm{MSF}$.

Usou-se o delineamento inteiramente casualizado, com quatro repetições, com cinco plantas cada, totalizando 20 plantas para cada tratamento. Os dados coletados foram submetidos à análise de variância simples e nos casos significativos foi aplicado o teste de Tukey ao nível de $5 \%$ de probabilidade para comparação de médias. Para as análises dos dados foram utilizados os programas Bioestat (Ayres et al., 2007) e planilha eletrônica.

\section{Resultados e discussão}

Durante os primeiros 120 dias após o início do experimento, as mudas de macacaporanga tiveram desempenho semelhante em relação à altura em todos os tratamentos (Figura 1A). Aos 180 dias observou-se diferença significativa entre os tratamentos $0 \%$ e $70 \%$ de sombreamento $(\mathrm{p}<0,05)$. A partir dos 240 dias, houve diferença significativa entre os tratamentos com $0 \%$ e $50 \%$ e $0 \%$ e $70 \%(\mathrm{p}<0,05)$ de sombreamento. As equações de regressão encontradas para o crescimento 
em altura para cada tratamento podem ser observadas na Tabela 1.

Para o diâmetro do colo verificou-se crescimento semelhante para todos os tratamentos até os 120 dias (Figura 1B). A partir dos 180 dias houve diferença

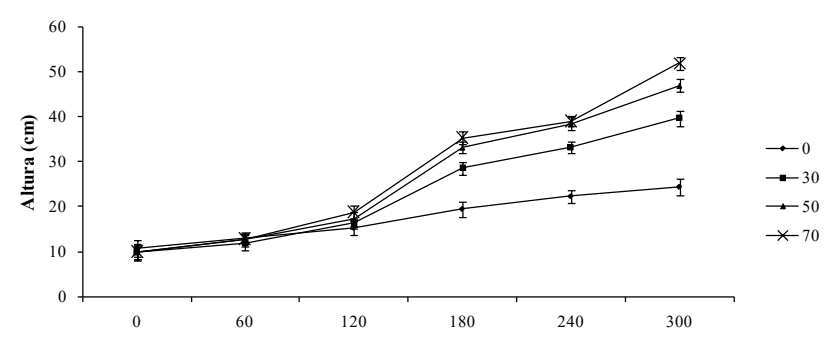

significativa entre o tratamento com $0 \%$ de sombreamento e todos os demais tratamentos $(p<0,05)$. As equações de regressão encontradas para o crescimento em diâmetro do colo para cada tratamento podem ser observadas na Tabela 1.

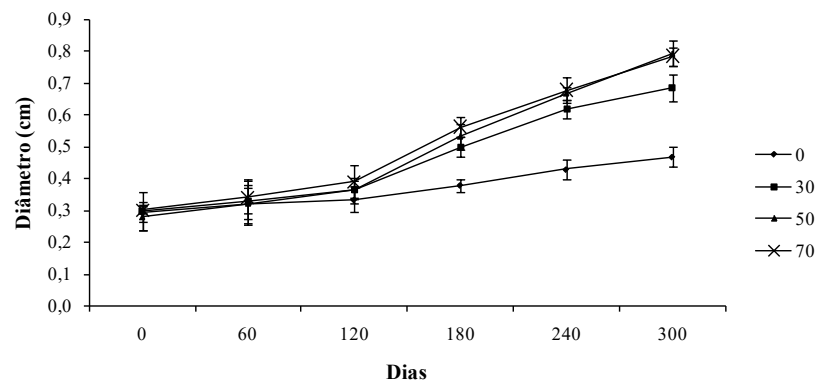

Figura 1. Crescimento em altura (A) e diâmetro do colo (B) de mudas de Aniba parviflora em diferentes níveis de sombreamento, em Santarém, PA.

Tabela 1. Equações de regressão de crescimento em altura e diâmetro do colo, e coeficientes de determinação $\left(\mathrm{R}^{2}\right)$ obtidas para os diferentes tratamentos de sombreamento em mudas de Aniba parviflora em Santarém, PA.

\begin{tabular}{ccc}
\hline $\begin{array}{c}\text { Sombreamento } \\
(\%)\end{array}$ & Equação & $\mathbf{R}^{\mathbf{2}}$ \\
\hline \multicolumn{3}{c}{ Altura } \\
\hline 0 & $\mathrm{y}=2,8789 \mathrm{x}-7,4573$ & 0,98 \\
30 & $\mathrm{y}=6,4451 \mathrm{x}-0,6987$ & 0,95 \\
50 & $\mathrm{y}=7,9617 \mathrm{x}-1,4293$ & 0,96 \\
70 & $\mathrm{y}=8,7154 \mathrm{x}-2,564$ \\
\hline \multicolumn{3}{c}{ Diâmetro do colo } \\
\hline 0 & $\mathrm{y}=0,0353 \mathrm{x}-0,2488$ \\
30 & $\mathrm{y}=0,0837 \mathrm{x}-0,1731$ & 0,96 \\
50 & $\mathrm{y}=0,1079 \mathrm{x}-0,1157$ & 0,94 \\
70 & $\mathrm{y}=0,1024 \mathrm{x}-0,1518$ & 0,95 \\
\end{tabular}

Os maiores valores para crescimento em altura e diâmetro do colo durante o período analisado foram nos tratamentos com $50 \%$ e $70 \%$ de sombreamento.

As maiores taxas de crescimento em ambientes sombreados foram encontradas para Jacaranda copaia com crescimento em altura, $54 \%$ superior ao tratamento com plena luz (Campos \& Uchida, 2002), Hymenaea courbaril L. var. stilbocarpa com crescimento em altura de $5 \mathrm{~cm}$ a $80 \%$ de sombreamento e $12 \mathrm{~cm}$ a $50 \%$ de sombreamento superior ao tratamento a pleno sol (Lima et al., 2010) e Dalbergia com aproximadamente $93 \mathrm{~cm}$ de altura superior ao tratamento com $0 \%$ de sombreamento (Pacheco et al., 2013). Rosa et al. (2009) observaram crescimento linear em altura até $70 \%$ de sombreamento em plantas de Schizolobium amazonicum diferente do encontrado no presente trabalho.

Aos 300 dias, os tratamentos com sombreamento foram superiores em relação ao controle quando analisou-se as variáveis: altura $(\mathrm{H})$, diâmetro do colo (D), número de folhas (NF), área foliar (AF) e área foliar específica (AFE). Os maiores valores para essas variáveis foram verificados no tratamento com $70 \%$ de sombreamento, exceto D e NF, em que os maiores valores foram observados com $50 \%$ de sombreamento. Para as variáveis AF e AFE não houve diferença significativa entre os tratamentos com $30 \%$ e $50 \%$ de sombreamento (Tabela 2).

Tabela 2. Incremento médio em altura $(\mathrm{H})$, incremento médio em diâmetro do colo (D), número de folhas (NF), área foliar (AF) e área foliar específica (AFE) de mudas de Aniba parviflora aos 300 dias, em Santarém, PA.

\begin{tabular}{cccccc}
\hline $\begin{array}{c}\text { Sombreamento } \\
(\%)\end{array}$ & $\mathbf{H}(\mathbf{c m})$ & $\mathbf{D}(\mathbf{c m})$ & $\mathbf{N F}$ & $\mathbf{A F}\left(\mathbf{c m}^{2}\right)$ & $\mathbf{A F E}\left(\mathbf{c m}^{2} \mathbf{~}^{-1}\right)$ \\
\hline 0 & $14,00 \pm 0,26 \mathrm{a}$ & $0,17 \pm 0,06 \mathrm{a}$ & $9,6 \pm 0,54 \mathrm{a}$ & $55,56 \pm 5,26 \mathrm{a}$ & $106,00 \pm 9,94 \mathrm{a}$ \\
30 & $30,42 \pm 0,36 \mathrm{~b}$ & $0,39 \pm 0,04 \mathrm{~b}$ & $24,8 \pm 1,30 \mathrm{~b}$ & $68,53 \pm 6,37 \mathrm{~b}$ & $113,19 \pm 9,28 \mathrm{~b}$ \\
50 & $42,26 \pm 0,30 \mathrm{c}$ & $0,51 \pm 0,07 \mathrm{c}$ & $31,4 \pm 0,54 \mathrm{c}$ & $67,80 \pm 6,53 \mathrm{~b}$ & $126,82 \pm 9,00 \mathrm{~b}$ \\
70 & $45,32 \pm 0,35 \mathrm{~d}$ & $0,40 \pm 0,07 \mathrm{~d}$ & $28,6 \pm 1,14 \mathrm{~d}$ & $96,96 \pm 8,84 \mathrm{c}$ & $307,35 \pm 19,96 \mathrm{c}$ \\
\hline
\end{tabular}

Médias seguidas da mesma letra na coluna não diferem entre si $(\alpha<0,05)$ pelo teste de Tukey. 
Em estudos realizados com jatobá (H. courbaril), fedegoso (Senna macranthera), moreira (Maclura tinctoria) (Almeida et al., 2005), andiroba (Virola surinamensis) (Lima et al., 2007), baru (Dipteryx alata) (Mota et al., 2012) e pau-ferro (Caesalpinia ferrea) (Lenhard et al., 2013), também foram verificadas maiores alturas em ambientes mais sombreados.

O maior crescimento das mudas em altura, quando sombreadas, pode ter ocorrido em razão do estiolamento induzido pela baixa intensidade luminosa, ou porque foi favorecido pelas temperaturas mais amenas nas folhas, devido à abertura dos estômatos e a fixação de carbono pelas plantas. Plantas cultivadas em condições de baixa disponibilidade de luz tenderiam a investir maior quantidade de fotoassimilados na parte aérea. Além disso, o maior alongamento celular contribuiria para maior altura sob ambientes sombreados (Wardlaw, 1990; Carvalho et al., 2006).

No entanto, algumas espécies, como Machaerium sp. (Batiston et al., 2008) e Tabebuia aurea (Oliveira \& Perez, 2012), apresentaram maior plasticidade para altura quando submetidas a diferentes intensidades luminosas, sem variação no porte das plantas.

$\mathrm{O}$ sombreamento induziu o aumento em diâmetro do colo das mudas, apresentando diferença entre os tratamentos. Entretanto, as mudas cultivadas em 50\% de sombreamento tiveram o maior incremento do diâmetro do colo (Tabela 1), quando comparadas com as cultivadas sob os demais tratamentos. As plantas cultivadas sob $50 \%$ de sombreamento apresentaram maior NF, seguidas pelos sombreamentos de $70 \%, 30 \%$ e $0 \%$, respectivamente. Verificou-se ainda que o aumento dos níveis de sombreamento promoveu maiores valores para AF, no entanto, os sombreamentos de $30 \%$ e $50 \%$ não foram estatisticamente distintos (Tabela 1).

Resultados semelhantes ao maior número de folhas e área foliar sob $50 \%$ de sombreamento foram encontrados por Silva et al. (2007), Câmara \& Endres (2008) e Azevedo et al. (2010).

$\mathrm{O}$ aumento da $\mathrm{AF}$ por folha individual nos maiores níveis de sombreamento é uma das maneiras da planta aumentar sua superfície fotossintetizante, assegurando maior aproveitamento de baixas intensidades luminosas (Pedroso \& Varela, 1995; Pacheco et al., 2013). A redução no nível de radiação pode fazer com que as plantas aumentem a proporção investida no crescimento em área foliar. Este aumento pode decorrer do aumento na expansão celular ao longo da lâmina foliar (Gobbi et al., 2011).
A AFE aumentou significativamente em função do aumento dos níveis de sombreamento (Tabela 2). O mesmo resultado foi encontrado para Handroanthus heptaphyllus (Borges et al., 2014), Swietenia macrophylla (Gonçalves et al., 2012; Azevedo \& Marenco, 2012), Minquartia guianensis (Azevedo \& Marenco, 2012), Bertholletia excelsa e Carapa guianensis (Azevedo, 2014), indicando que durante o desenvolvimento da planta o regime de luz pode afetar a estrutura foliar e partição de assimilados, sendo que as plantas cultivadas em baixa intensidade de luz muitas vezes têm folhas mais finas e maiores. Geralmente, estas alterações têm por objetivo aumentar a captação da luz incidente, aumentando a eficiência fotossintética da planta (Lambers et al., 1998).

$\mathrm{O}$ aumento da AFE pode ser considerado um fator importante na maximização do ganho de carbono por unidade de massa foliar, em condições de baixa luminosidade (Evans \& Poorter, 2001). Ele está relacionado com as alterações anatômicas que podem ocorrer nas plantas sombreadas, como cutículas e epiderme mais delgadas, menor espessura de mesofilo e menor proporção de parênquima paliçádico, de tecidos condutores e de sustentação, maior proporção de espaços intercelulares e menor densidade estomática (Berlyn \& Cho, 2000). A área foliar das espécies heliófitas aumenta com a elevação da radiação solar, ao passo que a área foliar de espécies tolerantes à sombra tende a aumentar em condições de baixa disponibilidade de radiação solar (Dale, 1988), indicando que macacaporanga se enquadra neste segundo grupo de plantas.

A redução da área foliar em plantas do tratamento controle pode ser considerada uma importante defesa contra a perda excessiva de água e danos no aparato fotoquímico, que poderia ser benéfica, uma vez que menos material vegetal é exposto a eventuais danos por excesso de luz, ou seja, a exposição prolongada a altas irradiâncias pode ser prejudicial às plantas, por absorverem mais luz do que podem utilizar, podendo ter como consequência a fotoinibição ou mesmo a morte da planta (Kitao et al., 2000; Dias \& Marenco, 2006; Cordeiro et al., 2009).

Os diferentes níveis de sombreamento afetaram as trocas gasosas nas plantas, como a taxa assimilatória líquida foliar $(A)$, condutância estomática $\left(g_{s}\right)$, transpiração $(E)$ e eficiência do uso da água (EUA), além do teor de clorofilas $a, b$ e total e razão $\mathrm{Cl} a / \mathrm{Cl} b$ no tecido foliar (Tabela 3 ). 
Os maiores valores de $A$ foram observados no sombreamento de $70 \%$, decrescendo com o aumento da intensidade luminosa (Tabela 3). Freitas et al. (2003) observaram em plantas de Coffea arabica L. que a 70\% de sombreamento a taxa de fotossíntese foi superior, mantendo-se com valores iguais em sombreamento de $50 \%$ e $30 \%$ e com decréscimo a pleno sol.

Tabela 3. Taxa assimilatória líquida foliar $(A)$, condutância estomática $(g s)$, transpiração $(E)$, eficiência no uso da água (EUA), Clorofilas $a(\mathrm{Cl} a), b(\mathrm{Cl} b)$, e total $(\mathrm{Cl}$ total) e razão clorofila $a / b(\mathrm{Cl} a / \mathrm{Cl} b)$ sob os níveis de $0 \%, 30 \%, 50 \%$ e 70\% de sombreamento, em plantas de Aniba parviflora, em Santarém, PA.

\begin{tabular}{|c|c|c|c|c|}
\hline Parâmetros & $0 \%$ & $30 \%$ & $50 \%$ & $70 \%$ \\
\hline$A\left(\mu \mathrm{mol} \mathrm{m} \mathrm{m}^{-2} \mathrm{~s}^{-1}\right)$ & $2,50 \pm 0,12 \mathrm{a}$ & $2,59 \pm 0,13 \mathrm{a}$ & $4,75 \pm 0,17 b$ & $5,95 \pm 0,18 \mathrm{c}$ \\
\hline$g_{s}\left(\mathrm{~mol} \mathrm{~m}^{-2} \mathrm{~s}^{-1}\right)$ & $0,080 \pm 0,003 \mathrm{a}$ & $0,049 \pm 0,002 b$ & $0,104 \pm 0,004 \mathrm{c}$ & $0,114 \pm 0,004 \mathrm{~d}$ \\
\hline$E\left(\mathrm{mmol} \mathrm{m} \mathrm{m}^{-2} \mathrm{~s}^{-1}\right)$ & $2,42 \pm 006 \mathrm{a}$ & $1,58 \pm 0,03 b$ & $3,04 \pm 0,02 \mathrm{c}$ & $3,40 \pm 0,06 \mathrm{~d}$ \\
\hline 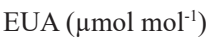 & $1,03 \pm 0,05 \mathrm{a}$ & $1,64 \pm 0,07 b$ & $1,56 \pm 0,06 \mathrm{c}$ & $1,75 \pm 0,05 \mathrm{~d}$ \\
\hline $\mathrm{Cl} a\left(\mu \mathrm{g} \mathrm{g}^{-1}\right)$ & $33,22 \pm 4,8 \mathrm{a}$ & $60,73 \pm 3,9 b$ & $107,49 \pm 5,2 \mathrm{c}$ & $178,29 \pm 7,6 \mathrm{~d}$ \\
\hline $\mathrm{Cl} b\left(\mu \mathrm{g} \mathrm{g}^{-1}\right)$ & $13,42 \pm 5,2 \mathrm{a}$ & $41,31 \pm 4,6 b$ & $63,67 \pm 6,9 c$ & $92,98 \pm 8,3 \mathrm{~d}$ \\
\hline $\mathrm{Cl} a / \mathrm{Cl} b$ & $2,49 \pm 0,36 \mathrm{a}$ & $1,48 \pm 0,19 b$ & $1,68 \pm 0,20 b c$ & $1,93 \pm 0,11 \mathrm{c}$ \\
\hline
\end{tabular}

Médias seguidas da mesma letra na linha não diferem entre si $(\alpha<0,05)$ pelo teste de Tukey.

Geralmente, plantas que crescem em ambientes com maior luminosidade apresentam taxas maiores de fotossíntese. Entretanto, em sombreamento onde capturam raios de luz podem ser mais produtivas, devido à menor taxa respiratória e foto-respiratória, principalmente quando ambientes com maior quantidade de luz causam a diminuição da condutância estomática, diminuindo a capacidade de controle térmico e perda de água (Berry \& Björkman, 1980; Chambers et al., 2004).

É provável que sob sombreamento tenha havido um controle eficiente da temperatura foliar e, consequentemente, do status hídrico da planta, de modo a permitir a otimização da atividade fotossintética e de turgescência, necessárias ao crescimento (Reis, 1991; Pacheco et al., 2013).

Os maiores valores de $g_{s}$ e $E$ ocorreram a $70 \%$ de sombreamento e as menores a 30\% (Tabela 3), o mesmo encontrado por Freitas et al. (2003). A taxa assimilatória líquida foliar e a eficiência de carboxilação podem ser refletidas pela condutância estomática, que é fortemente afetada pela intensidade luminosa (Costa \& Marenco, 2007).

Para macacaporanga, a maior taxa de $E$ foi a $70 \%$ de sombreamento, no entanto, estudos mostram que o aumento da irradiância pode promover as maiores taxas de transpiração (Welander \& Otosson, 2000; Pierezan et al., 2012) ou, a não alteração da mesma em diferentes níveis de sombreamento (Lima Júnior et al., 2006).

Com relação a EUA, a pleno sol observou-se a menor eficiência em relação aos demais tratamentos (Tabela 3). A maior perda de água no tratamento controle pode estar relacionada à manutenção da temperatura foliar, devido à exposição a maiores níveis de radiação, induzindo a maior perda de água para compensar o calor produzido pela energia radiante (Medina et al., 2002; Machado et al., 2005). Pode-se considerar que a redução do uso da água pelo decréscimo de $E$ foi motivada pelo fechamento parcial dos estômatos (Machado et al., 2009). O comportamento transpiratório de mudas em diferentes disponibilidades de luz pode ser variável. Em uma situação de boa disponibilidade de água, as plantas cultivadas geralmente apresentam altas taxas de transpiração. À medida que a água do solo se torna escassa, a planta começa a reduzir sua taxa transpiratória para diminuir a perda de água (Machado Filho, 2002; Kang et al., 2003).

Os teores de clorofias $a, b$ e total foram alterados significativamente, sendo que as plantas apresentaram maiores valores sob $70 \%$ e $50 \%$ de sombreamento (Tabela $2)$. Valores semelhantes foram encontrados por Souza et al. (2011), Lenhard et al. (2013) e Azevedo (2014), mostrando que a exposição prolongada das plantas à luz povocou a redução dos pigmentos fotossintéticos, como também pode ter induzido a fotoxidação. Plantas em condição de sombreamento tendem a aumentar a concentração de clorofila, para a maximização da captura de luz (Azevedo, 2014), com o aumento na proporção de clorofila $b$ em relação à $a$ (Critchley, 1999). Folhas cultivadas sob baixas intensidades de luz apresentam maiores teores de clorofila por unidade de peso, e folhas de sombra apresentam maior concentração de clorofila, quando comparadas às de sol. Uma possível 
justificativa para este comportamento é que as plantas que crescem sob baixas radiações apresentam melhor desenvolvimento do grana (Boardman, 1977).

Geralmente, a clorofila e os carotenóides tendem a aumentar com a redução da intensidade luminosa (Lenhard et al. 2013), sendo base para a otimização de fotofosforilação e, consequentemente, para a produção de energia. A clorofila $b$ capta energia de outros comprimentos de onda e a transfere para a clorofila $a$, que efetivamente atua nas reações fotoquímicas da fotossíntese. $\mathrm{O}$ aumento da clorofila $b$ nas folhas submetidas à baixa luminosidade representa um mecanismo de adaptação à condição de menor intensidade luminosa (Scalon et al., 2002). Este aumento também pode estar associado às maiores taxas de degradação da clorofila $a$ quando comparada às taxas de degradação da clorofila $b$ (Engel \& Poggiani, 1991). $\mathrm{O}$ aumento dos teores de clorofila nas folhas aumenta a capacidade fotossintética, tal como a luz na faixa do verde, presente em grande quantidade no interior do dossel das florestas (Rego \& Possamai, 2006).

Com relação à massa seca, foram observadas diferenças significativas para todos os tratamentos (Tabela 4). O sombreamento de $50 \%$ ocasionou o maior acúmulo na massa seca de raízes, caule, folhas e total. Esses resultados corroboram com os encontrados para Virola surinamensis (Lima et al., 2007), Mimosa caesalpiniifolia e Sterculia foetida (Câmara \& Endres 2008).

Tabela 4. Massa seca de raízes (MSR do caule (MSC), das folhas (MSF) e total (MST) e razão raiz/parte aérea (R/PA) de mudas de Aniba parviflora aos 300 dias, em Santarém, PA.

\begin{tabular}{ccccc}
\hline Sombreamento (\%) & $\mathbf{0 \%}$ & $\mathbf{3 0 \%}$ & $\mathbf{5 0 \%}$ & $\mathbf{7 0 \%}$ \\
\hline MSR (g) & $4,24 \pm 0,25 \mathrm{a}$ & $13,42 \pm 0,31 \mathrm{~b}$ & $17,72 \pm 0,13 \mathrm{c}$ & $16,44 \pm 0,27 \mathrm{~d}$ \\
MSC (g) & $2,18 \pm 0,13 \mathrm{a}$ & $6,60 \pm 0,28 \mathrm{~b}$ & $10,30 \pm 0,17 \mathrm{c}$ & $8,48 \pm 0,19 \mathrm{~d}$ \\
MSF (g) & $1,08 \pm 0,04 \mathrm{a}$ & $7,08 \pm 0,13 \mathrm{~b}$ & $10,50 \pm 0,10 \mathrm{c}$ & $9,98 \pm 0,06 \mathrm{~d}$ \\
MST (g) & $7,50 \pm 0,29 \mathrm{a}$ & $27,10 \pm 0,39 \mathrm{~b}$ & $38,52 \pm 0,19 \mathrm{c}$ & $34,90 \pm 0,36 \mathrm{~d}$ \\
R/PA & $1,30 \pm 0,01 \mathrm{a}$ & $0,98 \pm 0,04 \mathrm{~b}$ & $0,85 \pm 0,01 \mathrm{c}$ & $0,89 \pm 0,01 \mathrm{c}$ \\
\hline
\end{tabular}

Médias seguidas da mesma letra na linha não diferem entre si $(\alpha<0,05)$ pelo teste de Tukey.

Mudas de macacaporanga cultivadas sob 50\% e 70\% de sombreamento apresentaram maiores quantidades de massa seca foliar (Tabela 4), semelhante ao observado para Virola surinamensis (Lima et al., 2007) e Caesalpinia ferrea (Lenhard et al., 2013). Por outro lado, algumas espécies, como o jequitibá-rosa (Cariniana legalis) e cumaru-de-cheiro (Amburana cearensis), acumulam maior quantidade de biomassa foliar quando cultivadas sob luz plena (Ramos et al., 2004; Rego \& Possamai, 2006).

O maior valor para a MSF verificado no sombreamento de $50 \%$, esta relacionado com a maior quantidade de folhas (Tabela 2), semelhante ao encontrado por Aguiar et al. (2011). Felfili et al. (1999), trabalhando com Sclerolobium paniculatum, e Almeida et al. (2005) trabalhando com Maclura tinctoria, observam que a maior produção de massa seca foi obtida quando as mudas estavam sob $50 \%$ de sombreamento. Provavelmente à sombra, sob microclima mais ameno em termos de temperatura foliar, é possível que a alocação de carbono para ganho em massa foliar tenha sido concentrada neste compartimento, para aumentar a superfície foliar e compensar a eficiência fotossintética (Gonçalves et al., 2012).
Quanto à massa seca total, o maior ganho foi em 50\% de sombreamento (Tabela 4). Câmara \& Endres (2008), trabalhando com Mimosa caesalpiniifolia Benth. e Sterculia foetida L., observaram que os maiores ganhos foram a $50 \%$ de sombreamento, onde o maior número de folhas pode ter proporcionado uma maior quantidade de fotoassimilados produzidos, que foram translocados para o crescimento e para formação de massa seca (Silva et al., 2007).

A proporção de massa seca radicular aumentou nas plantas crescidas a $0 \%$ de sombreamento (Tabela 3). A razão raiz/parte aérea mais elevada em plantas de ambientes mais iluminados indica que a biomassa radicular é maior que a biomassa dos órgãos fotossintetizantes. Essa razão permite maior absorção de água e nutrientes (Claussen, 1996).

Nos níveis mais elevados de sombreamento, foram encontrados os maiores valores nos teores totais de clorofila e condutância estomática, aliados ao maior número de folhas, área foliar e área foliar específica, tendo como consequência maiores taxas fotossintéticas. Tal fato acarretou maior produção de massa seca e aumento no diâmetro e altura das plantas. Para C. 
guianensis, a maior taxa de crescimento foi atribuída às mais altas taxas fotossintéticas juntamente com o maior número de folhas e área foliar específica (Azevedo, 2014). Por outro lado, o aumento nos níveis de luz causou redução no crescimento em altura e diâmetro, no número de folhas e área foliar, consequentemente diminuição da massa seca total das plantas, fatores que podem estar relacionados com a elevação da temperatura e, desta forma, à intensificação na taxa respiratória, que pode induzir o fechamento dos estômatos, com consequente redução da fixação de carbono, causando, ainda, o aumento no consumo de fotoassimilados, além da fotodestruição ou fotodegradação dos pigmentos fotossintéticos.

Os parâmetros de crescimento inicial e morfofisiológicos encontrados podem indicar que a macacaporanca tem características de espécies ombrófilas em fases iniciais de sucessão, pois o tratamento a pleno sol pode representar uma condição de área de mata degradada e a condição de sombreamento de $50 \%$ pode representar uma condição de clareira em floresta natural.

\section{Conclusão}

Mudas de Aniba parviflora (Meisn.) Mez. apresentam o melhor desenvolvimento em condições de sombreamento com interceptação de $50 \%$ da irradiação solar, sugerindo que em condições naturais a espécie teria melhores chances de regeneração sob cobertura de mata, tolerando inclusive intensidades luminosas bastante reduzidas, em decorrência de um dossel fechado.

\section{Agradecimentos}

A Universidade Federal do Oeste do Pará- UFOPA, ao Centro de Energia Nuclear na Agricultura (CENA/ USP), a Divisão de Funcionamento de Ecossistemas Tropicais - DVECO (CENA/USP) e ao professor Dr. Lauro Barata.

\section{Referências}

Aguiar, F. F. A. et al. Crescimento de mudas de pau-brasil (Caesalpinia echinata Lam.), submetidas a cinco níveis de sombreamento. Revista Ceres, v. 58, n. 6, p. 729-734, 2011. DOI: 10.1590/S0034-737X2011000600008.

Aguilera, D. B. et al. Crescimento de Siegesbeckia orientalis sob diferentes condições de luminosidade. Planta Daninha, v. 22, n. 1, p. 43-51, 2004. DOI: 10.1590/S0100-83582004000100006.
Almeida, S. M. Z. et al. Alterações morfológicas e alocação de espécies florestais sob diferentes condições de sombreamento. Ciência Rural, v. 35, n. 1, p. 62-68, 2005. DOI: 10.1590/S010384782005000100010 .

Ayres, M. et al. (Ed.). BioEstat 5.0: aplicações estatísticas nas áreas das ciências médicas. 5. ed. Belém, PA: Sociedade Civil Mamirauá, 2007. 339 p.

Azevedo, I. M. G. et al. Estudo do crescimento e qualidade de mudas de marupá (Simarouba amara Aubl.) em viveiro. Acta Amazonica, v. 40, n. 1, p. 157-164, 2010. DOI: 10.1590/S004459672010000100020 .

Azevedo, G. F. C. \& Marenco, R. A. Growth and physiological changes in saplings of Minquartia guianensis and Swietenia macrophylla during acclimation to full sunlight. Photosynthetica, v. 50, n. 1, p. 86-94, 2012. DOI: 10.1007/s11099-012-0001-2.

Azevedo, G. F. C. Photosynthetic parameters and growth in seedlings of Bertholletia excelsa and Carapa guianensis in response to preacclimation to full sunlight and mild water stress. Acta Amazonica, v. 44, n. 1, p. 67-78, 2014. DOI: 10.1590/S0044-59672014000100007.

Batiston, D. A. et al. Crescimento inicial de Machaerium sp. (Leguminosae- Papilonoideae) em resposta a diferentes condições de sombreamento. Revista Eletrônica de Biologia, v. 1, n. 3, p. 8-20, 2008.

Bazzaz, F. A. \& Carlson, R. W. Photosynthetic acclimation t o variability in the light enviroment or early and late successinal plants. Oecologia, v. 54, p. 313-316, 1982. DOI: 10.1007/BF00379999.

Berlyn, G. P. \& Cho, J. Light, moisture, and nutrient use by plants. In: Ashton, M. S. \& Montagnini, F. (Ed.) The silvicultural basis for agroforestry systems. Boca Raton: CRC Press, 2000. p. 9-39.

Berry, J. \& Bjorkman, O. Photosynthetic response and adaptation to temperature in higher plants. Annual Review of Plant Physiology, v. 31, p.491-543, 1980. DOI: 10.1146/annurev.pp.31.060180.002423.

Boardman, N. K. Comparative photosynthesis of sun and shade plants. Annual Review of Plant Physiology, v. 28, p. 355-377, 1977. DOI: 10.1146/annurev.pp.28.060177.002035.

Borges, V. P. et al. Emergência e crescimento inicial de Tabebuia heptaphylla (Vell.) Toledo em ambientes contrastantes de luz. Revista Árvore, v. 38, n. 3, p. 523-531, 2014. DOI: 10.1590/S010067622014000300015 .

Bradshaw, A. D. Evolutionary significance of phenotypic plasticity in plants. Advances in Genetics, v. 13, p. 15-155, 1965. DOI: 10.1016/ S0065-2660(08)60048-6.

Brasil. Ministério do Meio Ambiente. Portaria $n^{\circ} 443$, de 17 de dezembro de 2014. Diário Oficial [da] República Federativa do Brasil, Brasília, DF, n. 245, p. 110-121, 18 dez. 2014.

Briggs, D. \& Walters, S. M. Plant variation and evolution. Cambridge: Cambridge University Press, 1997.

Câmara, C. A. \& Endres, L. Desenvolvimento de mudas de duas espécies arbóreas: Mimosa caesalpiniifolia benth. e Sterculia foetida sob diferentes níveis de sombreamento em viveiro. Floresta, v. 38, n. 1, p. 43-51, 2008. DOI: 10.5380/rf.v38i1.11026. 
Campos, M. A. A. \& Uchida, T. Influência do sombreamento no crescimento de mudas de três espécies amazônicas. Pesquisa Agropecuária Brasileira, v. 37, n. 3, p. 281-288, 2002. DOI: 10.1590/S0100-204X2002000300008.

Carvalho, N. O. S. et al. Crescimento inicial de plantas de licuri (Syagrus coronata (MART.) BECC.) em diferentes níveis de luminosidade. Revista Árvore, v. 30, n. 3, p. 351-357, 2006. DOI: 10.1590/S0100-67622006000300005.

Chambers, J. Q. et al. Respiration from a tropical forest ecosystem: partitioning of sources andlow carbon use efficiency. Ecological Applications, v. 14, n. 4, supl. p. s72-s88, 2004. DOI: 10.1890/016012 .

Claussen, J. W. Acclimation abilities of three tropical rainforest seedlings to an increase in light intensity. Forest Ecology and Management, v. 80, n. 1-3, p. 245-255, 1996. DOI: 10.1016/03781127(95)03606-7.

Cordeiro, Y. E. M. et al. Physiological and morphological responses of young mahogany (Swietenia macrophylla King) plants to drought. Forest Ecology and Management, v. 258, n. 7, p. 1449-1455, 2009. DOI: $10.1016 /$ j.foreco.2009.06.054.

Costa, G. F. \& Marenco, R. A. Fotossíntese, condutância estomática e potencial hídrico foliar em árvores jovens de andiroba (Carapa guianensis). Acta Amazonica, v. 37, n. 2, p. 229-234, 2007. DOI: 10.1590/S0044-59672007000200008.

Costa, L. G. S. et al. 1995. Pau-rosa - Aniba rosaeodora Ducke. Belém: FCAP, Serviço de Documentação e Informação, 1995. 15 p.

Critchley, C. Molecular adaptation to irradiance: the dual functionality of photosystem II. In: Singhal, G. S. et al. (Ed.). Concepts in photobiology: photosynthesis and photomorphogenesis New Delhi: Narosa Publishing House, 1999. p. 573-587.

Dale, J. E. The control of leaf expansion. Annual Review of Plant Physiology, v. 39, p. 267-295. 1988. DOI: 10.1146/annurev. pp.39.060188.001411.

Dias, D. P. \& Marenco, R. A. Photoinhibition of photosynthesis in Minquartia guianensis and Swietenia macrophylla inferred by monitoring the initial fluorescence. Photosynthetica, v. 44, n. 2, p. 235-240, 2006. DOI: 10.1007/s11099-006-0013-x.

Dutra, T. R. et al. Parâmetros fisiológicos de mudas de copaíba sob diferentes substratos e condições de sombreamento. Ciência Rural, v. 42, n. 7, 2012. DOI: 10.1590/S0103-84782012005000048.

Engel, V. L. \& Poggiani, F. Estudo da concentração de clorofila nas folhas e seu espectro de absorção de luz em função do sombreamento em mudas de quatro espécies florestais nativas. Revista Brasileira de Fisiologia Vegetal, n. 3, p. 39-45, 1991.

Evans, J. R. \& Poorter, H. Photosynthetic acclimation of plants to growth irradiance: the relative importance of specific leaf area and nitrogen partitioning in maximizing carbon gain. Plant, Cell and Environment, v. 24, n. 8, p. 755-767, 2001. DOI: 10.1046/j.13653040.2001.00724.x.

O Extrativismo do Pau-rosa (Aniba duckei Koster., Aniba rosaeodora Ducke): aspectos sócio-econômicos: a silvicultura da espécie. Belém, PA: SUDAM, 1972. p. 5-55. (SUDAM. Documentos da Amazônia, v. 3, n. 1-4).
Felfili, J. M. et al. Comportamento de plântulas de Sclerolobium paniculatum Vog. var. rubiginosum (Tul.) Benth. sob diferentes níveis de sombreamento, em viveiro. Revista Brasileira de Botânica, v. 22, n. 2, supl. 2, p. 297-301, 1999. DOI: 10.1590/ S0100-84041999000500011.

Freitas, R. B. et al. Influência de diferentes níveis de sombreamento no comportamento fisiológico de cultivares de café (Coffea arabica L.). Ciência e Agrotecnologia, v. 27, n. 4, p. 804-810, 2003.

Gobbi, K. F. et al. Área foliar específica e anatomia foliar quantitativa do capim-braquiária e do amendoim-forrageiro submetidos a sombreamento. Revista Brasileira de Zootecnia, v. 40, n. 7, p. 14361444, 2011. DOI: 10.1590/S1516-35982011000700006.

Gonçalves, J. F. C. et al. Efeito do ambiente de luz no crescimento de plantas jovens de mgno (Swietenia macrophylla King). Scientia Forestalis, v. 40, n. 95, p. 337-344, 2012.

Instituto Nacional de Meteorologia (Brasil). Normais climatológicas.

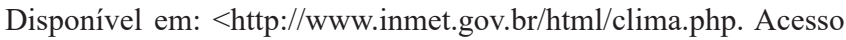
em: 1 jul. 2013.

Kang, S. Z. et al. Crop coefficient and ratio of transpiration to evapotranspiration of winter wheat and maiz in a semi-humid region. Agricultural Water Management, v. 59, n. 3, p. 239-254, 2003. DOI: 10.1016/S0378-3774(02)00150-6.

Kitajima, K. Relative importance of photosynthetic traits and allocation patterns as correlates of seedling shade tolerance of 13 tropical trees. Oecologia, v. 98, n. 3, p. 419-428, 1994. DOI: 10.1007/BF00324232.

Kitao, M. et al. Susceptibility to photoinhibition of three deciduous broadleaf tree species with different successional traits raised under various light regimes. Plant Cell and Environmental, v. 23, n. 1, p. 81-89, 2000. DOI: 10.1046/j.1365-3040.2000.00528.x.

Kubitzki, K. \& Renner, S. Lauraceae 1 (Aniba and Aiouea). New York: Botanical Garden, 1982. 125 p. (Flora Neotropica. Monograph, 31).

Lambers, H. et al. Plant physiological ecology. New York: SpringerVerlag, 1998. $540 \mathrm{p}$.

Lenhard, N. R. et al. Crescimento de mudas de pau-ferro sob diferentes níveis de sombreamento. Pesquisa Agropecuária Tropical, v. 43, n. 2, p. 178-186, 2013. DOI: 10.1590/S1983-40632013000200012.

Lichtenthaler, H. K. Chlorophylls and carotenoids: pigment photosynthetic biomembranes. Methods Enzymology, v. 148, p. 362-385, 1987. DOI: 10.1016/0076-6879(87)48036-1.

Lima, A. L. S. et al. Crescimento de Hymenaea courbaril L. var. stilbocarpa (Hayne) Lee et Lang. e Enterolobium contortisiliquum (Vell.) Morong (Leguminosae) sob diferentes níveis de sombreamento. Acta Amazonica, v. 40, n. 1, p. 43-48, 2010. DOI: 10.1590/S004459672010000100006.

Lima, J. D. et al. Efeito da intensidade da luz no crescimento de mudas de Virola surinames (Rol.) Warb. Ciências Exatas e da Terra, Ciências Agrárias e Engenharias, v. 13, n. 2, p. 39-45, 2007.

Lima, J. D. et al. Efeitos da luminosidade no crescimento de mudas de Caesalpinia ferrea Mart. ex Tul. (Leguminosae, Caesalpinoideae). Acta Amazonica, v. 38, n. 1, p. 5-10, 2008. DOI: 10.1590/S004459672008000100002. 
Lima Júnior, É. C. et al. Aspectos fisioanatômicos de plantas jovens de Cupania vernalis Camb. submetidas a diferentes níveis de sombreamento. Revista Árvore, v. 30, p. 33-41, 2006.

Lüttge, U. Physiological ecology of tropical plants. Berlim: Springer-Verlag, 1997.

Machado, E. C. et al. Respostas da fotossíntese de três espécies de citros a fatores ambientais. Pesquisa Agropecuária Brasileira, v.40, n. 12, p.1161-1170, dez. 2005. DOI: 10.1590/S0100204X2005001200002.

Machado Filho, J. A. Estudos ecofisiológicos de dois genótipos de mamoeiro (Carica papaya L.) cultivados sob condições de campo no cerrado baiano. 2002. 70 f. Dissertação (Mestrado em Agronomia) - Universidade de Brasília, Brasília.

Machado, R. S. et al. Respostas biométricas e fisiológicas ao deficit hídrico em cana-de-açúcar em diferentes fases fenológicas. Pesquisa Agropecuária Brasileira, v. 44, n.12, p.1575-1582, dez. 2009. DOI: 10.1590/S0100-204X2009001200003.

Maia, G. S \& Andrade, E. H. E. Database of the amazon aromatic plants and their essential oils. Química Nova, v. 32, n. 3, p. 595-622, 2009. DOI: 10.1590/S0100-40422009000300006.

Medina, C. L. et al. Photosynthetic response of citrus grown under reflective aluminized polypropylene shading nets. Scientia Horticulturae, v. 96, p. 115-125, 2002. DOI: 10.1016/S03044238(02)00085-7.

Mota, L. H. S. et al. Sombreamento na emergência de plântulas e no crescimento inicial de Dipteryx alata Vog. Ciência Florestal, v. 22, n. 3, p. 423-431, 2012. DOI: 10.5902/198050986611.

Oliveira, A. K. M. \& Perez, S. C. J. G. A. e. Crescimento inicial de Tabebuia aurea sob três intensidades luminosas. Ciência Florestal, v. 22 , n. 2, p. 263-273, 2012. DOI: 10.5902/198050985733.

Pacheco, F. V. et al. Crescimento inicial de Dalbergia nigra (Vell.) Allemão ex. Benth. (FABACEAE) e Chorisia speciosa A.St.-Hil (MALVACEAE) sob diferentes níveis de sombreamento. Revista Árvore, v. 37, n. 5, p. 945-953, 2013. DOI: 10.1590/S010067622013000500017.

Pedroso, S.G. \& Varela, V. P. Efeito do sombreamento no crescimento de mudas de sumauma (Ceiba pentandra (L.) Gaertn). Revista Brasileira de Sementes, v. 17, n.1, p.47- 51, 1995.

Pierezan, L. et al. Emergência de plântulas e crescimento de mudas de jatobá com uso de bioestimulante e sombreamento. Cerne, v. 18, n. 1, p. 127-133, 2012. DOI: 10.1590/S0104-77602012000100015.

Pintado, A. et al. Exploring phenotypic plasticity in the lichen Ramalina capitata: morphology, water relations and chlorophyll content in Northand South-facing populations. Annals of Botany, v. 80, p. 345- 353, 1997.

Ramos, K. M. O. et al. Desenvolvimento inicial e repartição de biomassa de Amburana cearenses (Allemao) A.C. Smith, em diferentes condições de sombreamento. Acta Botânica Brasílica, v. 2, n. 18, p. 351-358, 2004.
Rego, G. M. \& Possamai, E. Efeito do sombreamento sobre o teor de clorofi la e crescimento inicial do Jequitibá-rosa. Boletim de Pesquisa Florestal, n. 53, p. 179-194, 2006.

Reis, G. G. dos. Crescimento e ponto de compensação lumínico em mudas de espécies florestais nativas submetidas a diferentes níveis de sombreamento. Revista Árvore, v. 18, n. 2, p. 103-111, 1991.

Rodrigues, R. M. A Flora da Amazônia. Belém: CEJUP, 1989. $462 \mathrm{p}$.

Rosa, L. S. et al. Emergência, crescimento e padrão de qualidade de mudas de Schizolobium amazonicum Huber ex Ducke sob diferentes níveis de sombreamento e profundidades de semeadura. Revista Ciências Agrárias, n. 52, p. 87-98, 2009.

Santana, J. A. S. Distribuição espacial da regeneração natural de Aniba rosaeodora (Pau - rosa). Revista de Ciências Agrárias, n. 33, p. 37-48, 2000.

Santos, U. F. et al. Níveis de sombreamento na produção de mudas de pau-de-balsa (Ochroma pyramidale). Bioscience Journal, v. 30, n. 1, p. 129-136, 2014.

Scalon, S. de P. Q. et al. Crescimento inicial de mudas de espécies florestais nativas sob diferentes níveis de sombreamento. Revista Árvore, v. 26, n. 1, p. 1-5, 2002.

Silva, B. M. S. et al. Efeito da luz no crescimento de mudas de Hymenaea parvifolia Huber. Revista Árvore, v. 31, n. 6, p. 10191026, 2007. DOI: 10.1590/S0100-67622007000600006.

Souza, G. S. et al. Teores de pigmentos fotossintéticos, taxa de fotossíntese e estrutura de cloroplastos de plantas jovens de Mikania laevigata Schultz Bip. ex Baker cultivadas sob malhas coloridas. Semina: Ciências Agrárias, v. 32, supl. 1, p. 1843-1854, 2011. DOI: 10.5433/1679-0359.2011v32n4Sup1p1843.

Strauss-Debenedetti, S. \& Bazzaz, F. A. Photosynthetic characteristics of tropical trees along successional gradients. In: Mulkey, S. S. et al. (Ed.). Tropical forest plant ecophysiology. New York: Chapman \& Hall, 1996. p. 162-186.

Terashima, I. \& Hikosaka, K. Comparative ecophysiology of leaf and canopy photosynthesis. Plant, Cell and Environment, v. 18, p. 1111-1128, 1995. DOI: 10.1111/j.1365-3040.1995.tb00623.x.

Valladares, F. et al. Plastic phenotypic response to light of 16 congeneric shrubs from a Panamanian rainforest. Ecology, v. 81, p. 1925-1936, 2000. DOI: 10.1890/0012-9658(2000)081[1925:PP RTLO]2.0.CO;2.

Wardlaw, I. F. The control of carbon partitioning in plants. New Phytologist, v. 116 n. 3, p. 341-381, 1990. DOI: 10.1111/j.14698137.1990.tb00524.x.

Welander, N. T. \& Otosson, B. The influence of low light, droughtand fertilization on transpiration and growt in young seedllings of Quercus robur. Forest Ecology and Management, v. 127, n. 1-3, p. 139-51, 2000. DOI: 10.1016/S0378-1127(99)00126-7. 